\title{
Clinical challenges of glioma and pregnancy: a systematic review
}

\author{
A. van Westrhenen ${ }^{1,2,3}$ - J. T. Senders ${ }^{1,2} \cdot$ E. Martin $^{1,2} \cdot$ A. C. DiRisio ${ }^{2} \cdot$ M. L. D. Broekman ${ }^{1,2,4}$
}

Received: 16 January 2018 / Accepted: 22 February 2018 / Published online: 6 April 2018

(c) The Author(s) 2018

\begin{abstract}
Introduction This review aims to summarize challenges in clinical management of concomitant gliomas and pregnancy and provides suggestions for this management based on current literature.

Methods PubMed and Embase databases were systematically searched for studies on glioma and pregnancy. Observational studies and articles describing expert opinions on clinical management were included. The strength of evidence was categorized as arguments from observational studies, consensus in expert opinions, or single expert opinions. Risk of bias was assessed by the Newcastle-Ottawa Scale (NOS).

Results 27 studies were selected, including 316 patients with newly diagnosed $(n=202)$ and known $(n=114)$ gliomas during pregnancy. The median sample size was 6 (range 1-65, interquartile range 1-9). Few recommendations originated from observational studies; the remaining arguments originated from consensus in expert opinions.

Conclusion Findings from observational studies of adequate quality include (1) There is no known effect of pregnancy on survival in low-grade glioma patients; (2) Pregnancy can provoke clinical deterioration and tumor growth on MRI; (3) In stable women at term, there is no benefit of cesarean section over vaginal delivery, with respect to adverse events in mother or child. Unanswered questions include when pregnancy should be discouraged, what best monitoring schedule is for both mother and fetus, and if and how chemo- and radiation therapy can be safely administered during pregnancy. A multicenter individual patient level meta-analysis collecting granular information on clinical management and related outcomes is needed to provide scientific evidence for clinical decision-making in pregnant glioma patients.
\end{abstract}

Keywords Glioma $\cdot$ Glioma patient $\cdot$ Pregnancy $\cdot$ Pregnant patient $\cdot$ Clinical management

\section{Introduction}

Electronic supplementary material The online version of this article (https://doi.org/10.1007/s11060-018-2851-3) contains supplementary material, which is available to authorized users.

M. L. D. Broekman

M.L.D.Broekman-4@umcutrecht.nl

1 Department of Neurosurgery, University Medical Center Utrecht, Heidelberglaan 100, 3584 CX Utrecht, The Netherlands

2 Department of Neurosurgery, Brigham and Women's Hospital, Computational Neuroscience Outcomes Center, Harvard Medical School, 60 Fenwood Road, Boston, MA 02115, USA

3 Stichting Epilepsie Instellingen Nederland Heemstede, Achterweg 5, 2103 SW Heemstede, The Netherlands

4 Department of Neurosurgery, University Medical Center Utrecht, HP G03.124, PO Box 85500, 3508 GA Utrecht, The Netherlands
Improved prognosis in glioma patients has led to a greater number of young, female glioma patients becoming pregnant despite their diagnosis [1,2]. No increased risk of glioma development during pregnancy has been reported [3]. However, changes in glioma behavior during pregnancy have been described, including increased tumor volume and growth rates, earlier onset of symptoms, and increased frequency of seizures [2, 4-6]. In low-grade glioma (LGG) patients specifically, dedifferentiation and tumor progression during pregnancy has been found $[2,7,8]$.

Although exact incidence rates of gliomas during pregnancy are lacking, the incidence of primary malignant brain tumors in pregnant women is $2.6-15$ per $100,000[9,10]$. Due to this low incidence, evidence on clinical outcome and management of pregnant glioma patients has been based on small case series and expert opinions only. These studies 
include heterogeneous groups of patients and scarcely report on quality of life.

Pregnancy in glioma patients raises many difficult questions for their treatment team, ranging from: 'What anticonvulsant therapy is least teratogenic?' to 'When can delivery be induced?'. Although previous studies have provided potential management algorithms for gliomas in pregnancy, the evidence is sparse, and many questions remain unanswered $[2,11]$. This review aims to summarize challenges in clinical management of concomitant gliomas and pregnancy and to provide suggestions for this management based on current literature.

\section{Methods}

This review is conducted in accordance with the Preferred Reporting Items for Systematic Reviews and Meta-Analyses (PRISMA) statement [12].

\section{Search and study selection}

PubMed and Embase databases were systematically searched for studies on glioma and pregnancy, with the most recent search on December 3, 2016 [Supplementary Table 1]. Studies were included that evaluated clinical management in glioma patients diagnosed before or during pregnancy. Clinical management was defined as any step in the neurooncological treatment of glioma patients before, during or after pregnancy. Studies reporting on other brain tumors in addition to gliomas were also included, provided that they reported outcome data of glioma patients separately. Pre-clinical studies and studies not written in English were excluded. All studies that met inclusion criteria and were published in peer-reviewed journals were included, but published conference abstracts were excluded because they represent only a synopsis of scientific work that is presented in its entirety elsewhere. There were no restrictions regarding study design, in order to be as comprehensive as possible; therefore reviews and letters to the editor were also included. Eligible studies were selected by two independent authors (JS, EM) and disagreements were solved by discussion.

\section{Data extraction and analysis}

The following data was extracted: study design, patient population, tumor characteristics, and clinical course and management during pregnancy. Topics of interest, regarding clinical management during pregnancy, were selected beforehand and correlating recommendations were extracted and assessed according to the Oxford Centre for Evidencebased Medicine (CEBM) Levels of Evidence [Supplementary Table 2] [13]. A qualitative synthesis of results was provided, and findings were summarized in a narrative fashion. Because no central histopathological review has been made, it is not feasible to perform a cross comparison by histopathological subtype and tumor grade between the studies. Risk of bias among included studies was assessed using the Newcastle-Ottawa Scale (NOS) [14].

\section{Results}

The search strategy resulted in 1189 hits after removal of duplicates, and 27 studies were eligible for data extraction (Fig. 1). Included studies were predominantly case reports $(n=9)$ or case series $(n=14)$, with a median sample size of six patients (range 1-65, interquartile range 1-9). There were three expert opinion pieces and one cohort study. In total, 316 glioma patients were included, of whom 202 were diagnosed during pregnancy, and 114 before pregnancy. Eight studies evaluated brain tumor patients in general and included 26 non-glioma brain tumor patients in addition to glioma patients (Table 1). The WHO tumor grade ranged between I and IV. Here we describe different opinions on clinical decision-making in known and newly diagnosed gliomas during pregnancy (Table 2).

\section{Pre-pregnancy counseling}

Seven studies emphasize the importance of adequate counseling for glioma patients who express interest in becoming pregnant $[2,4,6,8,15-17]$. The exact content remains ambiguous because it is challenging to predict the outcomes associated with pregnancy in an individual case with sufficient accuracy.

One of the primary concerns is that pregnancy will trigger tumor growth and negatively influence prognosis of glioma patients, but there is no evidence to support this [2]. The largest cohort study included in this review did not find any evidence to suggest that overall survival in LGG is affected by pregnancy [17]. However, changes in tumor behavior, including tumor growth and dedifferentiation, have been described $[4,5]$. A case series of eight patients with diffuse glioma observed unfavorable tumor evolution in six cases during pregnancy [4]. Three out of five gliomas diagnosed before pregnancy presented with clinical worsening, increase in tumor growth, and change in histopathological grade [4]. A multicenter case series with different WHOgrade gliomas found clinical deterioration in $37.5 \%$ of cases during pregnancy and significant tumor progression on MRI, compared with pre-pregnancy values [2]. High-grade gliomas and gliomas with unfavorable molecular profile were particularly likely to be associated with tumor progression during pregnancy [2]. Some authors suggest discussing the 


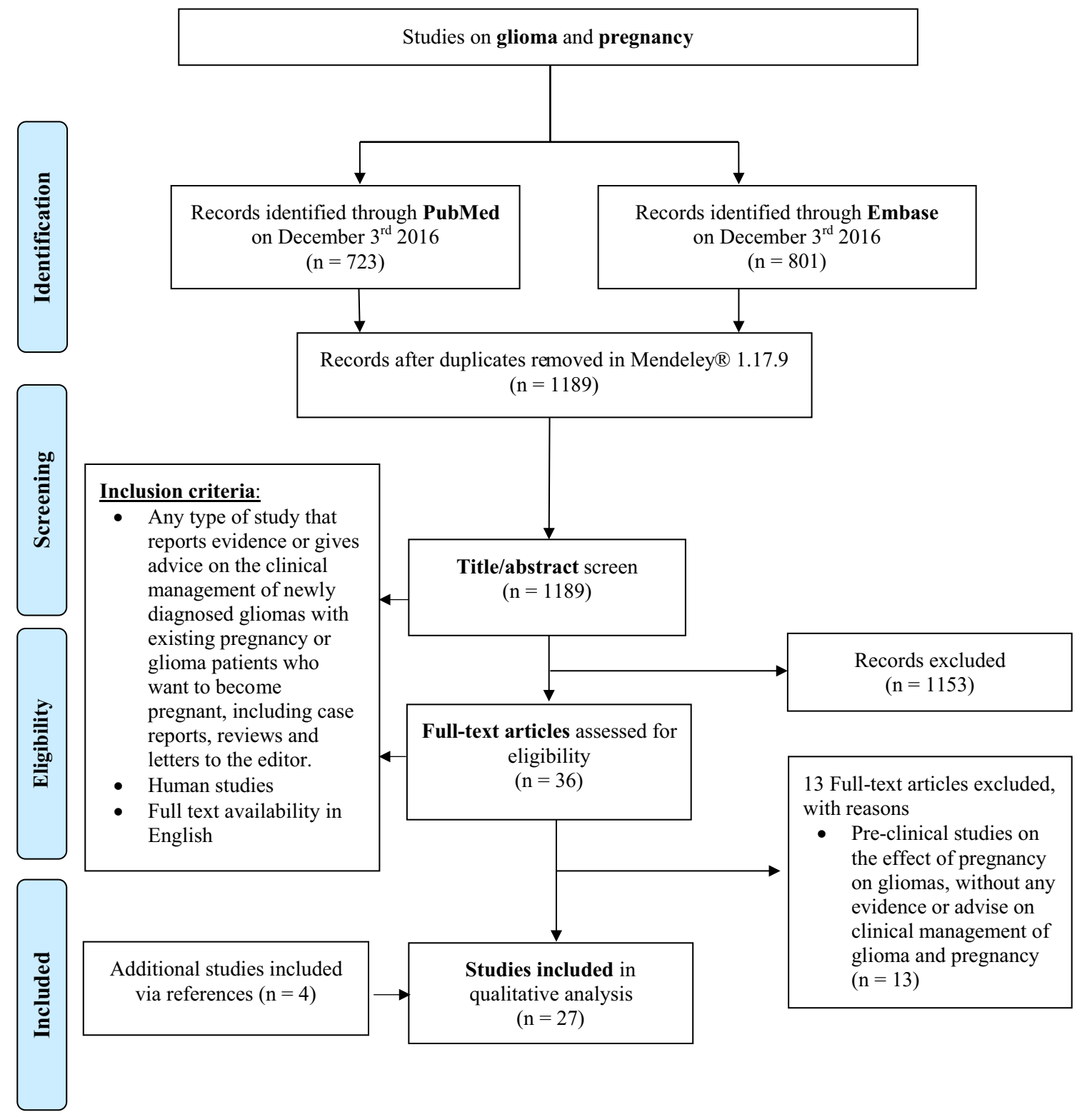

Fig. 1 Flowchart of study search and selection

risks and benefits of neuroimaging [15] and anticonvulsant therapies [2] before pregnancy.

\section{Timing of pregnancy}

Although teratogenicity of chemotherapy has not yet clearly been demonstrated, it is advisable to postpone pregnancy until after administration of these therapies [6]. The best timing of conception remains unclear, but a case report has shown that pregnancy and the birth of a healthy infant can occur as early as 3 weeks after the last chemotherapy and even after heavy pretreatment with alkylating agents [18].
Zwinkels et al. mentioned assisted reproductive technology in female glioma patients, but discouraged it since hormonal stimulation, using progesterone and gonadotropin hormones, could induce tumor growth and dedifferentiation [6].

\section{Monitoring}

Although no statement is made on the exact frequency of neurological and imaging monitoring, several studies agree that gliomas should be followed-up closely during pregnancy with repeated MRIs [2, 4-6, 15, 19]. Interestingly, no distinction in recommendations is made between different glioma 
Table 1 Characteristics of included studies

\begin{tabular}{|c|c|c|c|c|c|c|}
\hline Study & Study type & Population size & Median age* [range] & Tumor type & WHO-grade & $\begin{array}{l}\text { Known }(\mathrm{K}) / \\
\text { newly diag- } \\
\text { nosed }(\mathrm{N})\end{array}$ \\
\hline Peeters et al. [2] & Multicenter case series & 52 & $26.0[19-37]$ & $\begin{array}{l}\text { Glioma WHO II (32), } \\
\text { glioma WHO III } \\
\text { (14), glioma WHO } \\
\text { IV (6) }\end{array}$ & II-IV & $\mathrm{K}(24), \mathrm{N}(28)$ \\
\hline Kasai et al. [34] & Case report & 1 & 39 & Oligodendroglioma & II & $\mathrm{N} * *$ \\
\hline Pallud [16] & Letter to the editor & NA & NA & NA & NA & NA \\
\hline Rønning et al. [17] & Cohort study & 65 & $31.4 / 25.3^{\dagger \dagger}[16-40]$ & $\begin{array}{l}\text { Astrocytoma (37), } \\
\text { pilocytic astrocytoma } \\
\text { (12), oligodendro- } \\
\text { glioma (11), oligoas- } \\
\text { trocytoma (5) }\end{array}$ & I-II & $\mathrm{K}(25), \mathrm{N}(40)$ \\
\hline Umehara et al. [28] & Case report & 1 & 30 & Pylocytic astrocytoma & I & $\mathrm{K}$ \\
\hline Al-Rasheedy et al. [32] & Case report & 1 & 36 & GBM & IV & $\mathrm{K}$ \\
\hline Taylan et al. [10] & Case report & 1 & 21 & GBM & IV & $\mathrm{N}$ \\
\hline Abd-Elsayed et al. [25] & Case series & 7 & $36[29-40]$ & $\begin{array}{l}\text { LGG (2), HGG (2), } \\
\text { glioma (not speci- } \\
\text { fied) (1), GBM (1), } \\
\text { non-glial (1) }\end{array}$ & I-IV & $\mathrm{N}$ \\
\hline Daras et al. [8] & Case series & 3 & $27[15-39]$ & $\begin{array}{l}\text { Diffuse astrocytoma } \\
\text { WHO II (1), well } \\
\text { differentiated astro- } \\
\text { cytoma WHO II (1), } \\
\text { non-glial (1) }\end{array}$ & II & $\mathrm{K}$ \\
\hline Flechl et al. [18] & Case report & 1 & 37 & GBM & IV & $\mathrm{K}$ \\
\hline Gülşen et al. [30] & Case report & 1 & 30 & Gliosarcoma & IV & $\mathrm{N}$ \\
\hline Yust-Katz et al. [20] & Case series & 15 & $30 / 28^{\dagger \dagger}[24-38]$ & $\begin{array}{l}\text { Glioma WHO II (6), } \\
\text { glioma WHO III (6), } \\
\text { GBM (3) }\end{array}$ & II-IV & $\mathrm{N}$ \\
\hline Wu et al. [23] & Case series & 2 & {$[25-42]$} & Glioma WHO III & III & $\mathrm{N}$ \\
\hline \multirow[t]{2}{*}{ Zwinkels et al. [6] } & $\begin{array}{l}\text { Case series }+ \\
\text { Retrospective cohort }\end{array}$ & 7 & 29 [15-37] & $\begin{array}{l}\text { Astrocytoma (3), } \\
\text { oligoastrocytoma (2), } \\
\text { ependymoma (1), } \\
\text { pleiomorphic xan- } \\
\text { thoastrocytoma (1) }\end{array}$ & I-II & K (6), N (1) \\
\hline & & 103 & NA & LGG (53), HGG (50) & I-III & K (28), N (75) \\
\hline Scarrott et al. [24] & Case report & 1 & 32 & GBM & IV & $\mathrm{K}$ \\
\hline Lynch et al. [7] & $\begin{array}{l}\text { Retrospective case } \\
\text { series }\end{array}$ & 10 & 33 [25-37] & $\begin{array}{l}\text { Astrocytoma WHO } \\
\text { II (3), oligodendro- } \\
\text { glioma WHO II (1), } \\
\text { non-glial (6) }\end{array}$ & II & $\mathrm{N}$ \\
\hline Lew et al. [22] & Letter to the editor & 1 & 26 & GBM & IV & $\mathrm{N}$ \\
\hline Pallud et al. [5] & Case series & 11 & $25.5[21.5-38.5]$ & WHO II gliomas & II & $\mathrm{K}$ \\
\hline Johnson et al. [15] & Case series & 22 & Mean $31.7 / 32.1^{\dagger \dagger}$ & $\begin{array}{l}\text { Astrocytoma (5), oli- } \\
\text { godendroglioma (2), } \\
\text { ependymomas (2), } \\
\text { mixed glioma (2), } \\
\text { non-glial (10) }\end{array}$ & II & K (13), N (9) \\
\hline Pallud et al. [4] & $\begin{array}{l}\text { Retrospective case } \\
\text { series }\end{array}$ & 8 & 27 [18-33] & $\begin{array}{l}\text { Oligodendroglioma } \\
\text { WHO II (4), oligo- } \\
\text { dendroglioma WHO } \\
\text { III (1), astrocytoma } \\
\text { WHO II (1), astrocy- } \\
\text { toma WHO III (1), } \\
\text { unknown (1) }\end{array}$ & II-III & K (5), N (3) \\
\hline
\end{tabular}


Table 1 (continued)

\begin{tabular}{|c|c|c|c|c|c|c|}
\hline Study & Study type & Population size & Median age* [range] & Tumor type & WHO-grade & $\begin{array}{l}\text { Known }(\mathrm{K}) / \\
\text { newly diag- } \\
\text { nosed }(\mathrm{N})\end{array}$ \\
\hline Blumenthal et al. [19] & Case series & 6 & 28 [24-33] & $\begin{array}{l}\text { Anaplastic astrocytoma } \\
\text { (2), anaplastic oli- } \\
\text { godendroglioma (1), } \\
\text { oligodendroglioma } \\
\text { (1), oligoastrocytoma } \\
\text { (1), GBM (1) }\end{array}$ & II-IV & $\mathrm{N}$ \\
\hline Mackenzie et al. [27] & Case report & 1 & 48 & GBM & IV & $\mathrm{N}$ \\
\hline $\begin{array}{l}\text { Stevenson and Thomp- } \\
\text { son [29] }\end{array}$ & Literature review & NA & NA & NA & NA & NA \\
\hline Haba et al. [31] & Case report & 1 & 33 & Anaplastic astrocytoma & III & $\mathrm{N}$ \\
\hline Tewari et al. [11] & Case series & 8 & 24 [19-37] & $\begin{array}{l}\text { GBM (4), anaplastic } \\
\text { astrocytoma (3), non- } \\
\text { glial (1) }\end{array}$ & III-IV & $\mathrm{N}$ \\
\hline Isla et al. [26] & Case series & 7 & $32[28-38]$ & $\begin{array}{l}\text { Ependymoma (2), low } \\
\text { grade astrocytoma } \\
(2), \text { non-glial (2), } \\
\text { unknown (1) }\end{array}$ & II & $\mathrm{N}$ \\
\hline Nishio et al. [21] & $\begin{array}{l}\text { Retrospective case } \\
\text { series }\end{array}$ & 6 & 29 [23-35] & $\begin{array}{l}\text { Malignant epend- } \\
\text { ymoma (1), anaplas- } \\
\text { tic astrocytoma (1), } \\
\text { pilocytic astrocytoma } \\
\text { (1), non-glial (3) }\end{array}$ & I-III & $\mathrm{N}$ \\
\hline
\end{tabular}

$L G G$ low-grade glioma, $H G G$ high-grade glioma, GBM glioblastoma multiforme, WHO World Health Organization, $N A$ not applicable

*In years, at glioma diagnosis

*** Pregnancy discovered 1 week after diagnosis. $\dagger$ Parity after diagnosis: $0 / \geq 1$

${ }^{\dagger}$ Newly diagnosed / known glioma

WHO grades, despite their variability in treatment regimens and prognosis. Zwinkels et al. emphasize the advantages of a routine follow-up MRI at 32-36 weeks of gestation, since both induction of labor, as well as tumor therapy, can be initiated at this point if indicated [6]. No deleterious consequences of MRI or CT neuroimaging have been reported, but iodine compounds of CT contrast agents might induce fetal hypothyroidism [15]. Some argue that gadolinium should not be administered during pregnancy unless there is an essential clinical indication [20], while others state that contrast agents increase diagnostic yield and should therefore not be withheld [15]. Rigorous obstetrical monitoring is advised, but no detailed guidelines are provided $[5,6,21]$. Five studies indicate the importance of multidisciplinary management at a tertiary care center for optimal neurological and obstetrical care $[10,15,22-24]$. Prenatal screening has not been addressed in any study.

\section{Neuro-oncological treatment options and timing}

\section{Surgery}

Indication for neurosurgery highly depends on tumor location, size, type, neurological signs and symptoms, gestational period, and the patient's preferences $[6,25]$. If the patient is in a stable condition, several authors suggest to postpone surgery at least until after the first trimester [22, 23, 25-27], or even after 24 [25] or 30 [7] weeks of gestation, to permit gestational advancement. If there is a clear indication for surgery, the second trimester seems to be the ideal time, since the fetus may be too vulnerable during the first, and the risk of intraoperative hemorrhage is increased during the third trimester [10, 11, 23]. Surgical intervention seems inevitable when the neurological condition of the patient declines and signs of intracranial 
Table 2 Considerations for clinical decision-making in pregnant glioma patients

Timing in clinical decision-making Considerations

Pre-pregnancy counseling

Monitoring

Neuro-oncological treatment
Evidence based on observational studies

- Pregnancy may increase the risk of tumor growth, dedifferentiation and recurrence in glioma patients $[4,6,8,15]$

- Pregnancy does not influence overall survival in LGG [17]

- Pregnancy followed by birth of a healthy infant can occur three weeks after the last chemotherapy in a glioblastoma [18]

\section{Expert opinions}

- Use adequate pre-pregnancy counseling for all glioma patients who express the wish to become pregnant [2, 4, 6, 8, 15-17], and discuss

- The possibility of tumor growth, dedifferentiation and recurrence $[4,6,7,15] \quad 5$

- The benefit-to-risk ratio for mother and fetus [4] 5

- The pros and cons of anticonvulsant therapies and neuroimaging during pregnancy $[2, \quad 5$ 15]

- Counsel all female patients with LGG in their reproductive years, regardless of the deci- 5 sion to become pregnant [17]

- Postpone pregnancy until chemo- or radiation therapy has finished [6]

- Pregnancy is not recommended in patients with HGG, untreated glioma, glioma under treatment, progressive residual tumors, clinical deterioration, uncontrolled seizures or gliomas with an unfavorable molecular profile [2]

- Hormonal stimulation for IVF is not recommended [6]

Expert opinions

- Closely follow-up of glioma patients during pregnancy, with repeated MRIs and rigorous 5 obstetrical monitoring in a tertiary care center with multidisciplinary management for optimal neurological and obstetrical care is recommended [2, 4, 6, 15, 19, 21-23]

- Apply routine follow-up MRI at 32-36 weeks of gestation, so that labor as well as tumor 5 therapy can be scheduled [6]

- Gadolinium should not be administered during pregnancy unless there is an essential clini- 5 cal indication [20]

- Contrast agents increase diagnostic yield and should therefore not be withheld [15] 5

Evidence based on observational studies

- It is safe to postpone surgery when the patient is in stable condition [22, 23, 25-27] 4

- Surgery can be safely performed after the first trimester [10, 11, 23] 4

- Alkylator-based chemotherapy (PCV or TMZ) administered for the treatment of a glio- 4 blastoma during the first trimester can result in the birth of a healthy infant [18]

Expert opinions

- Indication for neurosurgery is highly dependable on tumor site, size and type, neurological 5 signs and symptoms, gestational period and the patient's wishes $[6,25]$

- Postpone surgery after the first trimester, preferably after delivery, when the patient is in 5 stable condition [8, 22, 23, 25-27]

- Surgical intervention is inevitable when condition of the patient declines with changes in 5 mental state $[2,6,8,10,25,28,29]$

- Risk of biopsy outweighs risk of inadequate treatment [8, 11, 29-31] 5

- The second trimester seems to be the ideal timing for surgery [10, 11, 23] 5

- Avoid nitrous oxide and isoflurance [25]—Do not perform surgery before 24 or 30 weeks 5 of gestation $[8,25]$

- Apply radiation therapy only after the first trimester and minimize the scattering dose $<10 \mathrm{mV}$, with axial plane trough the head and shielding of the pelvis $[11,19,31]$

- Avoid chemotherapy during the first trimester, especially PCV (probarbazine, lomustine and vincristine), carmustine (Gliadel) is presumed to be relatively safe in pregnant glioma patients [19]

- Apply dorsal decubitus position, with trunk rotation to the left and avoid ventral decubitus 5 position during surgery [8] 
Table 2 (continued) monitored closely $[6,26,34]$

Expert opinions

- The benefit of preventing and treating epileptic seizures outweighs the teratogenic effects 5 of anticonvulsants [8, 11, 22, 26, 27, 34]

- Lamotrigine, levetiracetam and carbamazepine monotherapy should be considered as first 5 choice $[6,8,11]$

- Anticonvulsant treatment should be optimized before conception [19] 5

- After delivery, the anticonvulsant dosages should be re-adjusted to the original dose 5 within two to three days [6]

- When prescribing anticonvulsants that interfere with vitamin $\mathrm{K}$ absorption, treat mother 5 and born child with vitamin $\mathrm{K}$ [19]

- Apply corticosteroids during the second and third trimester of pregnancy $[8,11,25,27] \quad 5$

- Avoid chronic use of dexamethasone during pregnancy [25, 26] 5

- Prescribe prednisolone when lung maturation is not preferred [31] 5

- Betamethasone is preferred over dexamethasone, because of fewer side effects [10] 5

Obstetrical treatment

Evidence based on observational studies

- No benefit of CS over vaginal delivery is described, when the mother is at term and in 4 stable condition $[2,5,11,25,27]$

Expert opinions

- CS should be performed at fetal maturation, when the patient's condition declines and, if 5 the patient is stable enough, before tumor resection [22, 23, 28]

- Delivery at 34-36 weeks of gestation is preferable [21, 23]

- Apply CS under general anesthesia to reduce risk of cerebral herniation $[6,11,16,27]$

- Apply CS in nulliparous women, because of their risk of increased intracranial pressure 5 during delivery [21]

- Apply CS and tumor resection under the same general anesthesia to minimize the risk for 5 mother and child $[11,23]$

- Apply CS and tumor resection in two different sessions to allow for maternal-fetal bonding 5 [27]

- Avoid mannitol and hypocapnia to prevent fetal dehydration and cerebral ischemia respec- 5 tively [25]

- Epidural anesthesia can be given to shorten the second phase of delivery and decrease risk 5 of increased intracranial pressure [27]

- After delivery, treat the women as a non-pregnant patient, according to the WHO-treat- 5 ment criteria $[2,21]$

CEBM (Oxford Centre for Evidence-based Medicine-Levels of Evidence), 4: Case series and poor quality cohort studies, 5: Expert opinion $L G G$ low-grade glioma, $H G G$ high-grade glioma, $C S$ Cesarean section, $P C V$ probarbazine, lomustine and vincristine, $T M Z$ temozolomide

hypertension or changes in mental state occur $[2,6-8,25$, $28,29]$. In newly diagnosed brain tumors during pregnancy, prompt tissue diagnosis via tumor biopsy is recommended by multiple groups. The risk of biopsy outweighs the risk of inadequate treatment [7, 11, 29-31]. To prevent aorto-caval compression during surgery, a dorsal decubitus position, with a trunk rotation to the left is advised, and ventral decubitus position should be avoided [7].

\section{Anesthesia}

It is controversial whether many anesthetic agents can be used safely during pregnancy. Some suggest avoiding nitrous oxide and isoflurance, because several case series showed their possible teratogenicity [25]. The neonatal neurotoxic effect of desflurance and sevoflurance needs to be further examined [25]. Propofol seems to be relatively safe as the main side effect is relaxing of the uterus, but seizures, ataxia, 
and hallucinations have been reported in the newborn when exposure exceeded six hours [25]. Whether it is necessary to monitor a fetus intraoperatively when viability is reached, remains a matter of debate [15].

\section{Radiotherapy}

In glioma patients, the fetus can be exposed to radiation by scattering [21]. Especially during the first trimester, therapeutic cerebral irradiation can cause serious harm to the fetus and should, therefore, be avoided [15, 22, 25, 26]. Radiation doses $>50 \mathrm{cGy}$ pose a risk to the fetus during all trimesters [19]. Authors advise to calculate and minimize the scattered dose by using coplanar beams $<10 \mathrm{mV}$, with an axial plane through the head, and additional shielding of the pelvis [11, 19, 31].

\section{Chemotherapy}

Evidence from animal and epidemiological studies suggest that chemotherapy can cause serious teratogenicity, especially during the first trimester [7, 29, 32]. A review on chemotherapy exposure during pregnancy found chemotherapy-associated malformations in 9 out of 71 (12.7\%) children, which is more than four times higher compared to the general population [33]. High risks of fetal malformation after PCV (procarbazine, lomustine, and vincristine) chemotherapy exposure during the first trimester are described [19]. The use of carmustine wafers (Gliadel) are presumed to be relatively safe in pregnant glioma patients, but no evidence was reported on systemic use of carmustine [19]. Evidence is poor and information on long-term effects on the child is lacking [6]. A case series of six malignant glioma patients with chemotherapy exposure during the first trimester, however, showed delivery of healthy babies [19]. As long as there is no consensus on the actual risk of chemotherapy during pregnancy, authors recommend to avoid it if there is no strong indication [7, 29].

\section{Medical treatment options (other than chemotherapeutic agents) for symptom reduction/prevention}

\section{Anticonvulsants}

Convulsive seizures in pregnant glioma patients can cause hypoxia and fetal acidosis. Several authors agree that the benefit of preventing and treating these seizures properly, outweighs the teratogenic effects of anticonvulsants [7, 11, $22,26,27,34]$. Lamotrigine, levetiracetam, and carbamazepine monotherapy are suggested to be favorable, because of their low teratogenic risk. Long term side effects of levetiracetam and lamotrigine, however, are insufficiently examined $[6,7,11]$. Several groups advise monitoring serum levels of anticonvulsants, since they can fluctuate during pregnancy [6, 26, 34]. The current American Academy of Neurology guidelines states that the anticonvulsant treatment should be optimized before conception, and vitamin $\mathrm{K}$ supplements should be given to mother and child if the choice of anticonvulsants is one which impairs vitamin $\mathrm{K}$ absorption [19]. After delivery, it is advised to re-adjust the anticonvulsant dosages to the original dose within 2-3 days [6].

\section{Corticosteroids}

Several authors encourage the administration of corticosteroids during the second and third trimester to promote fetal lung maturation $[7,11,25,27]$. Prednisolone is advised when lung maturation is not a priority, [31] and dexamethasone is considered safe in the acute setting [25, 26]. For chronic use, betamethasone is preferred over dexamethasone, because of a better side effect profile [10].

\section{Anticoagulants}

Especially in high-grade glioma patients, the risk of venous thromboembolism (VTE) is increased [35]. Pregnancy itself also increases risk of VTE, so pregnant glioma patients may benefit from prophylactic anticoagulation, but specific guidelines are lacking [36, 37].

\section{Obstetrical treatment options and timing}

To decrease the risk of increased intracranial pressure (ICP) during delivery, some recommend the use of epidural anesthesia [27], whereas others advise a cesarean section (CS) over vaginal delivery in nulliparous women [21]. This beneficial effect of CS has not been proven in literature $[2,5,12$, 25]. Two case series did not find altered child development or adverse clinical outcome of the mother, related to the method of delivery $[2,5]$. Therefore, several authors agree that there is no clinical benefit of CS over vaginal delivery if the mother is at term and in stable condition $[2,5,11,25$, 27].

The timing of delivery depends on individual risks of the effect of pregnancy on the tumor and benefits of fetal maturation. If the patient is stable, authors advise to induce delivery at fetal maturation, and if possible, before neurosurgery [22, 23, 28]. A gestational age of 34-36 weeks has been proposed as ideal timing [21,23]. CS at an earlier stage could, however, provide more time for adjuvant treatment [27]. If the patient deteriorates with signs of increased ICP and the child is viable, most agree to perform a CS $[15,19,20,25$, 27]. CS under general anesthesia is recommended because this reduces the risk of cerebral herniation $[6,11,15,27]$. 
Some studies advise performing CS and tumor resection under the same general anesthesia to minimize the risk of cerebral herniation and anesthesia for mother and child, [11, 23] while another study recommends performing two different sessions to allow for maternal-fetal bonding following the delivery [27].

After delivery, it is advised to treat the woman as a nonpregnant patient, according to the WHO-treatment criteria, and to discuss breastfeeding, contraceptives, and adaptation of anticonvulsants $[2,21]$.

\section{Risk of bias among included studies}

According to the NOS score, four studies were at low risk of bias [Supplementary Table 3] [2, 17, 19, 21]. All other included studies were at high risk of bias, mainly due to low generalizability of the exposed cases and lack of a control group.

\section{Discussion}

Gliomas during pregnancy are rare, but it is important to have an adequate treatment strategy. The majority of recommendations included in this review originate from expert opinions without supporting evidence from observational studies (Table 2). Rønning et al. (2016) performed a cohort study with low risk of bias and observed no association between pregnancy and survival in LGG patients. Peeters et al. [2] performed a multicenter case series with low risk of bias and found (1) Clinical deterioration and tumor progression on MRI of gliomas during pregnancy and (2) No observed benefit of CS over vaginal delivery with respect to adverse events, in stable women at term. These observations were also found in smaller case series with a high risk of bias [4-6, 11, 15, 25, 27]. All other recommendations and conclusions are reported in studies with a high risk of bias and should be interpreted with caution.

Other cancer types raise similar questions for the treatment team during pregnancy, and especially long-term outcomes of children with prenatal exposure to cancer and treatment are lacking. A multicenter, prospective case-control study involving 129 children with prenatal exposure to different types of cancer and treatment, reported no significant difference in neurocognitive and cardiac outcome, compared to matched controls [38]. The estimated fetal radiation dose and number of chemotherapy cycles were not related to the children's outcome. However, median followup was 22 months, which does not reveal long-term developmental problems, chemotherapy was only administered after the first trimester, and no new targeted therapies were applied [38]. Another cohort study found a higher risk of preterm labor and small-for-gestational-age children after fetal chemotherapy exposure [39]. Both studies reported no increased incidence of congenital malformations after chemotherapy during pregnancy [38, 39]. The Physician Data Query (PDQ) guideline for breast cancer treatment and pregnancy advises to avoid chemotherapy and radiotherapy in the first trimester and to minimize scattering radiation dose to the fetus, which is in line with our findings [40]. After the first trimester, many chemotherapeutic drugs are safe to administer, but trastuzumab is contraindicated, according to the PDQ [40].

One in 200 women who attend prenatal clinics are receiving anticonvulsant treatment [41]. A large cross-sectional observational study from the United Kingdom examined the effect of monotherapy epilepsy treatment during pregnancy [42]. Lamotrigine and levetiracetam were associated with the lowest risk of congenital malformations (e.g. spina bifida and cardiac anomalies), whereas valproate was associated with the highest risk [42]. These results were confirmed by a meta-analysis on the safety of anti-epileptic drugs for neurological development in exposed children, which showed that only valproate was significantly associated with developmental delay [43]. A systematic review including eight studies on levetiracetam exposure in the second and third trimester could not find an increased overall risk of major malformation or adverse events on long-term child development, compared to the general population [44]. Two cohort studies on lamotrigine use during pregnancy reported no significant findings regarding the incidence of neurodevelopmental disorders $[45,46]$. The above findings are in line with the findings from our review.

Specific evidence-based guidelines for the use of general anesthesia during pregnancy are lacking, but it is the consensus to perform surgery under general anesthesia when an untreated condition poses a high risk to mother or child. Although adverse events are rarely reported in the literature, one study showed that surgery during the first trimester might increase the risk of congenital malformations or miscarriage [47].

\section{Limitations}

Most findings presented in this review are based on low empirical evidence. The included studies are often limited by small sample sizes, high risk of bias, and a low level of evidence. Multiple recent studies are from the same French glioma study group, which may have influenced the findings.

Many aspects of the clinical management of pregnant glioma patients remain a topic of debate [Supplementary Table 4]. Unanswered questions address issues as to when pregnancy should be discouraged, what the best monitoring schedule is for both mother and fetus, if and how chemo- and radiation therapy can be safely administered during pregnancy, and what the best delivery mode is. Moreover, it's 
important to examine the long-term effects of different treatment strategies on the child's well-being. Therefore, an individual patient-level meta-analysis is needed to investigate the conclusions and recommendations made by individual studies. Additionally, multicenter prospective registries are required that collect granular information on clinical management and related outcomes. These efforts can provide the necessary evidence for clinical decision-making in pregnant glioma patients.

\section{Conclusion}

Clinical decision-making in glioma and pregnancy remains a great challenge for the treatment team. Very few findings are based on clinical observations originating from case series or cohort studies with low risk of bias. These include: (1) There is no known effect of pregnancy on survival in LGG patients; (2) Pregnancy can provoke clinical deterioration and tumor growth on MRI; (3) There is no benefit of CS over vaginal delivery with respect to adverse events in mother or child among stable pregnant women at term. Most recommendations originate from expert opinions or case reports and should be interpreted with caution. An individual patient data meta-analysis, as well as the inclusion of obstetric variables in (neuro-)oncological registries, could facilitate evidence-based decision-making in pregnant glioma patients.

\section{Compliance with ethical standards}

Conflict of interest The authors declare that they have no competing interests.

Open Access This article is distributed under the terms of the Creative Commons Attribution 4.0 International License (http://creativeco mmons.org/licenses/by/4.0/), which permits unrestricted use, distribution, and reproduction in any medium, provided you give appropriate credit to the original author(s) and the source, provide a link to the Creative Commons license, and indicate if changes were made.

\section{References}

1. Claus EB, Black PM (2005) Survival rates and patterns of care for patients diagnosed with supratentorial low-grade gliomas: Data from the SEER program, 1973-2001. Cancer 106(6):1358-1363

2. Peeters $S$, Pagès $M$, Gauchotte $G$ et al (2017) Interactions between glioma and pregnancy: insight from a 52-case multicenter series. J Neurosurg. 128:1-11

3. Zong H, Xu H, Geng Z et al (2014) Reproductive factors in relation to risk of brain tumors in women: an updated meta-analysis of 27 independent studies. Tumor Biol 35(11):11579-11586

4. Pallud J, Duffau H, Razak RA et al (2009) Influence of pregnancy in the behavior of diffuse gliomas: clinical cases of a French glioma study group. J Neurol 256(12):2014-2020
5. Pallud J, Mandonnet E, Deroulers C et al (2010) Pregnancy increases the growth rates of World Health Organization Grade II Gliomas. Ann Neurol 67(3):398-404

6. Zwinkels H, Dörr J, Kloet F, Taphoorn MJB, Vecht CJ (2013) Pregnancy in women with gliomas: a case-series and review of the literature. J Neurooncol 115:293-301

7. Lynch JC, Gouvêa F, Emmerich JC et al (2011) Management strategy for brain tumour diagnosed during pregnancy. Br J Neurosurg 25(2):225-230

8. Daras M, Cone C, Peters KB (2014) Tumor progression and transformation of low-grade glial tumors associated with pregnancy. $\mathrm{J}$ Neurooncol 116(1):113-117

9. Bondy ML, Scheurer ME, Malmer B et al (2008) Brain tumor epidemiology: consensus from the brain tumor epidemiology consortium. Cancer 113(7):1953-1968

10. Taylan E, Akdemir A, Zeybek B, Ergenoglu AM (2015) Recurrent brain tumor with hydrocephalus in pregnancy. J Obstet Gynaecol Res 41(3):464-467

11. Tewari KS, Cappuccini F, Asrat T et al (2000) Obstetric emergencies precipitated by malignant brain tumors. Am J Obstet Gynecol 182(5):1215-1221

12. Moher D, Liberati A, Tetzlaff J, Altman DG, Grp P (2009) Preferred reporting items for systematic reviews and meta-analyses: the PRISMA statement. PLoS Med 6(7):e1000097

13. Phillips B, Ball C, Sackett D et al Oxford Centre for Evidencebased Medicine-Levels of Evidence. http://www.cebm.net/oxfor d-centre-evidence-based-medicine-levels-evidence-march-2009/

14. Wells GA, Shea B, O'Connel D (2009) The Newcastle-Ottawa scale (NOS) for assessing the quality of non randomised studies in meta-analyses. http://www.ohri.ca/programs/clinical_epidemiolo gy/oxford.htm

15. Johnson N, Sermer M, Lausman A, Maxwell C (2009) Obstetric outcomes of women with intracranial neoplasms. Int J Gynecol Obstet 105(1):56-59

16. Pallud (2016) Pregnancy, epilepsy, and glioma survival. J Neurosurg 125:518

17. Ronning PA, Helseth E, Meling TR, Johannesen TB (2016) The effect of pregnancy on survival in a low-grade glioma cohort. J Neurosurg 125:393-400

18. Flechl B, Hassler MR, Kopetzky G, Balcke P, Kurz C, Marosi C (2013) Pregnancy in a patient with recurrent glioblastoma. F1000Research 2(246):2-7

19. Blumenthal DT, Parreño MGH, Batten J, Chamberlain MC (2008) Management of malignant gliomas during pregnancy: a case series. Cancer 113(12):3349-3354

20. Yust-katz S, De Groot JF, Liu D et al (2014) Pregnancy and glial brain tumors. Neuro Oncol 16(9):1289-1294

21. Nishio S, Morioka T, Suzuki S et al (1996) Primary brain tumours manifesting during pregnancy: presentation of six cases and a review of the literature. J Clin Neurosci 3(4):334-337

22. Lew PS, Tan WC, Tan WK, Tan HK (2010) Dilemmas in management of brain tumours in pregnancy. Ann Acad Med 39(1):64-65

23. Wu J, Ma Y-H, Wang T-L (2013) Glioma in the third trimester of pregnancy: two cases and a review of the literature. Oncol Lett 5(3):943-946

24. Scarrott LJ, Raina A, Madej T, Rajesh U (2012) Recurrent glioblastoma multiforme in pregnancy. J Obstet Gynaecol (Lahore) 32(7):704-705

25. Abd-Elsayed AA, Díaz-Gómez J, Barnett GH et al (2013) A case series discussing the anaesthetic management of pregnant patients with brain tumours. F1000Research 2(92):1-14

26. Isla A, Alvarez F, Gonzalez A, García-Grande A, Perez-Alvarez M, García-Blazquez M (1997) Brain tumor and pregnancy. Obstet Gynecol 89(1):19-23

27. Mackenzie AP, Levine G, Garry D et al (2005) Glioblastoma multiforme in pregnancy. J Matern neonatal Med 17(1):81-83 
28. Umehara T, Okita Y, Nonaka M et al (2016) A case of pilocytic astrocytoma requiring tumor resection during pregnancy. Mol Clin Oncol 4:567-570

29. Stevenson CB, Thompson RC (2005) The clinical management of intracranial neoplasms in pregnancy. Clin Obstet Gynecol 48(1):24-37

30. Gülsen I, Ak H, Yilmaz T, Bulut MD, Alkis I, Bayram I (2014) Recurrent gliosarcoma in pregnancy. Case Rep Neurol Med 2014:10-13

31. Haba Y, Twyman N, Thomas SJ, Overton C, Dendy P, Burnet NG (2004) Radiotherapy for glioma during pregnancy: fetal dose estimates, risk assessment and clinical management. Clin Oncol $16: 210-214$

32. Al-Rasheedy IM, Al-Hameed FM (2015) Advanced case of glioblastoma multiforme and pregnancy: an ethical dilemma. Neurosciences 20(4):388-391

33. Schapira DV, Chudley AE (1984) Successful pregnancy following continuous treatment with combination chemotherapy before conception and throughout pregnancy. Cancer 54:800-803

34. Kasai M, Aoki S, Kobayashi N, Hirahara F, Takahashi T (2016) Status epilepticus due to brain tumor during pregnancy. Clin Case Rep 4(4):333-335

35. Cote DJ, Dawood HY, Smith TR (2016) Venous thromboembolism in patients with high-grade glioma. Semin Thromb Hemost 42(8):877-883

36. Fogerty AE (2017) Challenges of anticoagulation therapy in pregnancy. Curr Treat Options cardiovac Med 19(10):76

37. Fuller KP, Turner G, Polavarapu S, Prabulos AM (2013) Guidelines for use of anticoagulation in pregnancy. Clin Lab Med 33(2):343-356

38. Amant F, Vandenbroucke M, Verheecke M et al (2015) Pediatric outcome after maternal cancer diagnosed during pregnancy. $\mathrm{N}$ Engl J Med 373(19):1824-1834
39. Van Calsteren K, Heyns L, De Smet F, Van Eycken L, Gziri MM (2010) Cancer during pregnancy: an analysis of 215 patients emphasizing the obstetrical and the neonatal outcomes. J Clin Oncol 28(4):683-689

40. PDQ Adult Treatment Editorial Board. Breast Cancer Treatment and Pregnancy (PDQ $\left.{ }^{\circledR}\right)$ : Health Professional Version. PDQ Cancer Information Summaries

41. Holmes LB, Harvey EA, Coull BA et al (2001) The teratogenicity of anticonvulsant drugs. N Eng J Med 344(15):1132-1138

42. Bromley RL, Calderbank R, Cheyne CP et al (2016) Cognition in school-age children exposed to levetiracetam, topiramate, or sodium valproate. Neurology 87(18):1943-1953

43. Veroniki AA, Rios P, Cogo E et al (2017) Comparative safety of antiepileptic drugs for neurological development in children exposed during pregnancy and breast feeding: a systematic review and network meta-analysis. BMJ Open 7(7):e017248

44. Chaudhry SA, Jong G, Koren G (2014) The fetal safety of Levetiracetam: a systematic review. Reprod Toxicol 46:40-45

45. Cohen-Israel M, Berger I, Martonovich EY, Klinger G, Stahl $\mathrm{B}$, Linder N Short- and long-term complications of in utero exposure to lamotrigine. Br J Clin Pharmacol. 2017. https://doi. org/10.1111/bcp. 13437

46. Diav-Citrin O, Shechtman S, Zvi N, Finkel-Pekarsky V, Ornoy A (2017) Is it safe to use lamotrigine during pregnancy? A prospective comparative observational study. Birth Defects Res 109(15):1196-1203

47. The Rapid Response Service. Anaesthetic agents in pregnant women undergoing non-obstetric surgical or endoscopic procedures: a review of the safety and guidelines. CADTH 